Original Article

\title{
The effectiveness of short-term high-intensity exercise on ventilatory function, in adults with a high risk of chronic obstructive pulmonary disease
}

\author{
Omar Farouk Helal ${ }^{1)}$, Mansour Abdullah Alshehri ${ }^{1{ }^{*}}$, Mohamed Salaheldien Alayat ${ }^{2)}$, \\ Hammad Alhasan ${ }^{1}$, Abdullah Tobaigy ${ }^{3)}$ \\ 1) Physiotherapy Department, Faculty of Applied Medical Sciences, Umm Al-Qura University: \\ PO Box 715, Postal Code 21421, Makkah, Saudi Arabia \\ 2) Department of Basic Sciences, Faculty of Physical Therapy, Cairo University, Egypt \\ 3) College of Medicine and Health, University College Cork, Ireland
}

\begin{abstract}
Purpose] This study sets out to investigate whether a short-term high-intensity arm ergometer exercise plan can be of benefit to adults whose poor ventilatory function places them at risk of developing chronic obstructive pulmonary disease. [Subjects and Methods] A pre-experimental design with a convenience sample was employed. The study enrolled 30 adult smokers, aged between 18-25 years old, all of whom were at a high risk of chronic obstructive pulmonary disease. The participants did a daily 20 -minute high-intensity arm ergometer exercise, at $75 \%$ target heart rate, at the same time over a period of three days. The forced vital capacity test manoeuvre was carried out before the sessions, and once all three had been done. [Results] The study demonstrated a sizeable increase in the mean values of forced vital capacity and forced expiratory volume in one second. The mean values of expiratory volume in one second/forced vital capacity as well as peak expiratory flow rate were not significant statistically. [Conclusion] Although further studies, using larger sampling groups, need to be carried out, this research demonstrates that adults at high risk of chronic obstructive pulmonary disease improve lung function by following shortterm high-intensity arm ergometer exercise.

Key words: Ventilatory function, Aerobic exercise, Chronic obstructive pulmonary disease
\end{abstract}

(This article was submitted Jan. 30, 2017, and was accepted Feb. 20, 2017)

\section{INTRODUCTION}

Over one billion people currently smoke tobacco, a majority of whom live in the developing world. Tobacco is thus the most widespread legal recreational drug, in spite of its known dangers to health ${ }^{1}$. Five million people die from smoking every year, and just under 50\% of long-term smokers die from diseases -including those which arise from ventilatory impairment - precipitated by smoking tobacco, when compared to non-smokers' mortality rates ${ }^{2}$. Teenagers and adolescents in the developing world are particularly vulnerable, since over half of them have begun smoking by the age of $18^{3)}$. Currently, the prevalence of smoking in Saudi Arabia ranges from 2.4-52.3\% (median=17.5\%) and it is varied based on age groups as follows: school students (ranges from 12-29.8\%; median=16.5\%), university students (ranges from 2.4-37\%; median $=13.5 \%$ ), adults (ranges from $11.6-52.3 \%$; median $=22.6 \%$ ) elderly people $(25 \%)^{4)}$. In addition, the prevalence of smoking in males (ranges from 13-38\%; median=26.5\%) is higher than females (ranges from 1-16\%; median=9\%) ${ }^{4}$ ).

In the west, smoking has been identified as the main risk factor of both lung cancer and chronic obstructive pulmonary

*Corresponding author. Mansour Abdullah Alshehri (E-mail: mamshehri@uqu.edu.sa)

(C2017 The Society of Physical Therapy Science. Published by IPEC Inc.

This is an open-access article distributed under the terms of the Creative Commons Attribution Non-Commercial No Derivatives (by-nc-nd) License. (CC-BY-NC-ND 4.0: http://creativecommons.org/licenses/by-nc-nd/4.0/) 
disease (COPD). Statistics from the UK demonstrate that $78 \%$ of people who died from COPD, and $84 \%$ of those who died from lung cancer, were smokers ${ }^{5}$. Ventilatory impairment is also linked to cigarette smoking, and it results in forced expiratory volume in one second $\left(\mathrm{FEV}_{1}\right)$ impairment in children, as well as impacting negatively on the lung function development of young adults ${ }^{6}$. Adults with tacky ventilator function are more likely to develop COPD than their peers. COPD leads to a drop in general physical ability and has a negative influence on the health related quality of life (HRQL) of affected individuals - and has been isolated as the third highest cause of death, worldwide ${ }^{7}$. It is clear, therefore, that young adults need to have good ventilatory function, in order to avoid the complications and consequences of having a poor respiratory system.

COPD patients have shown marked improvements in HRQL and exercise capacity when following a program of pulmonary rehabilitation (PR). If patients undertake regular exercise, this enlarges the heart muscle, so more blood is pumped around the body with every beat, thereby raising the amount of oxygen which is inhaled and can be used by the body's tissues. Exercise has a number of other positive effects: it increases the tidal volume, improves breathing rates, improves perfusion to all parts of the lungs and reduces ventilation of dead space. These factors all have a positive impact on young adults' respiratory systems ${ }^{8)}$.

High intensity training is thus a crucial part of rehabilitation for patients who have pulmonary diseases, since they improve both their functional abilities and their psychological status ${ }^{9}$. Thus rehabilitation programs should include treadmill or track walking, rowing, stair stepping, cycling, elliptical trainers and arm ergometer exercises, to improve lung and body functions ${ }^{9)}$. Before introducing an exercise program, certain preliminary steps need to be taken, for example, to determine the optimum level of intensity and how long the exercise should last. A simple calculation is useful, measuring $\mathrm{VO}_{2}$ max and subsequently training at a level which is greater or equal to $50 \%$ of $\mathrm{VO}_{2}$ max. Training sessions can last between 30 and 60 minutes, but it has been shown that high intensity exercise sessions of 20 minutes or more provide the best results ${ }^{10)}$.

A number of studies have proved that exercise training is very useful in improving respiratory systems ${ }^{5,10-14)}$. However, these pieces of research have tended to focus on the long-term, intermediate effects of exercise programs on respiratory systems, rather than how short term exercise training impacts on ventilatory function - in particular on adults who are at high risk of developing COPD.

This study aimed to:

- Examine the effectiveness of short-term high-intensity arm ergometer exercise on ventilatory function parameters in people with a high-risk of developing COPD.

- Create a specific exercise training programme for people suffering from respiratory diseases, drawing on the body of evidence available, and ensure it is specifically designed for patients who may only be in hospital and under supervision in the short-term.

- Produce a report, which underscores how smoking affects adults' lung function parameters, so that this information can be used to bolster anti-smoking campaigns.

\section{SUBJECTS AND METHODS}

The study was approved by the research committee of physical therapy department, Faculty of Applied Medical Sciences in Umm Al-Qura University, Makkah, Saudi Arabia. Approved Number: FAMS20160319. A pre-experimental design with a convenience sample was employed. All the study participants signed consent forms before being enrolled. The group consisted of 30 adult males, ranging from 18 to 25 years old, who were at high risk of developing $\mathrm{COPD}\left(\mathrm{FEV}_{1} / \mathrm{FVC}\right.$ ratio $<0.7$ and $\mathrm{FEV}_{1}-\%$ predicted $-\geq 80 \%$ ). The participants were asked to fill in a ventilatory function questionnaire from which their clinical data could be extracted. Once this was done, the exclusion criteria included: history of cardiopulmonary diseases and anyone with spinal deformities, condition which could have an impact on sub-optimal lung function results, ie: acute chest or abdominal pain, oral or facial aches that would be aggravated by using a mouthpiece, stress incontinence and dementia, history of exercise-induced bronchospasm and physically disabled adults.

The study was introduced and explained to the participants, who were then encouraged to handle the spirometer and arm ergometer devices. Both the pre and post exercise routine spirometry tests took place at the same time of day. In order to find a baseline for the study, participants provided a number of demographics: age, gender, height and body mass index (BMI). These were then used to work out their normal lung function values, using normative equations. Finally, each participant had his vital signs taken, and documented before the program began.

Spirometry - or the ventilator function test-records how a person inhales and exhales volumes of air within a given timeframe. Four variables were measured in the study: forced vital capacity (FVC), forced expiratory volume at the end of the first second $\left(\mathrm{FEV}_{1}\right), \mathrm{FEV}_{1} / \mathrm{FVC}$ ratio and peak expiratory flow rate (PEFR) by using a spirometer both before and after the participants had carried out three sessions of high intensity arm ergometer exercise. The $\mathrm{FEV}_{1}$ readings evidenced the conductive and resistive features of the large airways. The FVC measured the contractility of the participant's expiratory muscles and the PEFR was used to evaluate the performance of the respiratory muscles.

The arm ergometer resembles a bicycle for the arms, since participants are seated in a supportive chair and told to hold onto the handles in front of them and turn them in a circle, using their arms. Each participant carried out this exercise for 20 minutes, at precisely the same time of day, over a period of three days, at $75 \%$ target heart rate. To decide on the target heart rate, participants had their resting heart rate measured, and then this was fed into a formula used to predict maximum heart rate. This method of producing an age predicted maximum heart rate was originally mooted in the Journal of the American 
Table 1. Smokers students' respiratory parameters

\begin{tabular}{|c|c|c|c|c|c|c|c|}
\hline & \multicolumn{2}{|c|}{$\begin{array}{c}\mathrm{FEV}_{1} \\
\text { Mean } \pm \mathrm{SD}\end{array}$} & \multicolumn{2}{|c|}{$\begin{array}{c}\text { FVC } \\
\text { Mean } \pm \text { SD }\end{array}$} & \multicolumn{2}{|c|}{$\begin{array}{c}\text { PEFR } \\
\text { Mean } \pm \text { SD }\end{array}$} & $\begin{array}{l}\mathrm{FEV}_{1} / \mathrm{FVC} \\
\mathrm{Mean} \pm \mathrm{SD}\end{array}$ \\
\hline \multirow[t]{2}{*}{ Pre } & $\begin{array}{c}\text { Smokers } \\
\text { values }\end{array}$ & $\begin{array}{l}\text { Normal predicted } \\
\text { value }\end{array}$ & $\begin{array}{c}\text { Smokers } \\
\text { values }\end{array}$ & $\begin{array}{l}\text { Normal predicted } \\
\text { value }\end{array}$ & $\begin{array}{l}\text { Smokers } \\
\text { values }\end{array}$ & $\begin{array}{c}\text { Normal predicted } \\
\text { value }\end{array}$ & \multirow{2}{*}{$75.0 \pm 16.5$} \\
\hline & $4.0 \pm 0.8^{*}$ & $4.4 \pm 0.6^{*}$ & $4.9 \pm 0.9$ & $4.9 \pm 0.4$ & $471.6 \pm 150^{*}$ & $575.9 \pm 63.3^{*}$ & \\
\hline Post & \multicolumn{2}{|c|}{$3.6 \pm 0.7^{*}$} & \multicolumn{2}{|c|}{$4.5 \pm 0.9 *$} & \multicolumn{2}{|c|}{$482.6 \pm 141.9$} & $78.1 \pm 6.3$ \\
\hline
\end{tabular}

$\mathrm{FEV}_{1}$ : forced expiratory volume at the end of the first second; FVC: forced vital capacity; PEFR: peak expiratory flow rate; $\mathrm{FEV}_{1} /$ FVC: forced expiratory volume at the end of the first second/ forced vital capacity ratio $* \mathrm{p}<0.05$

College of Cardiology and the formula is as follows $(208-0.7 \times$ age $)$. Next, each participant's high intensity exercise target heart rate $(\mathrm{THR})$ was calculated thus: THR $=[($ Max HR - Resting HR $) \times 75 \%]+$ Resting Heart rate. It was decided to use of power output of 5.2 Newton, so the participants had to meet this by pedalling at 15 -gear resistance. The actual speed of the cycling depended on the target heart rate zone, and was adjusted accordingly.

Statistical analysis used SPSS software. The participants' age, weight and height were gathered and documented as \pm standard deviation (SD). In order to compare the pre and post treatment mean values of the four variables that were included in this study, paired t-tests were used. The unpaired t-test, in contrast, was used to analyse the study variables by comparing them with the normal predicted variables of an age-matched group. Differences between the two groups were deemed important at $\mathrm{p}>0.05$.

\section{RESULTS}

This study enrolled 30 students from the physical therapy department of the faculty of applied medical sciences. The participants had a mean age of $21.32 \pm 1.26$ years, BMI $27.48 \pm 3.92 \mathrm{~kg} / \mathrm{m}^{2}$ and a mean cigarettes smoking of 20.45 per day. Spirometries (FVC, FEV $1, \mathrm{FEV}_{1} / \mathrm{FVC}$ ratio and PEFR) were applied both before and after the three consecutive days program of three sessions of high intensity arm ergometer exercises. The results showed: a major and meaningful rise in the mean of $\mathrm{FEV}_{1}$, when comparing the post-test to the pre-test values. There was also a significant rise in the FVC, but there was no meaningful change in the mean values of the $\mathrm{FEV}_{1} / \mathrm{FVC}$ and PEFR between pre and post treatment (Table 1). Table 1 also shows that there was a significant gap between smokers and predicated values, demonstrating abnormal lung function parameters, an important risk factor for COPD.

\section{DISCUSSION}

A number of studies have been carried out in the past to investigate whether physical activity and sport exercises influence pulmonary function in patients who suffer from respiratory problems and issues. This study does not emulate other research, since it sets out to discover whether pulmonary function tests have different results in response to high-intensity arm ergometer exercises. Pre-test and post-test findings were documented and analysed, revealing an important change in FEV ${ }_{1}$ and PEFR between predicted values, and smokers' readings. This demonstrates abnormal lung function parameters in the group of smokers, which is a significant risk factor for developing COPD. The difference in the $\mathrm{FEV}_{1}$ and $\mathrm{FVC}$, pre and post test results, was statistically significant - which was not the case when comparing the pre- and post-test values of $\mathrm{FEV}_{1} / \mathrm{FVC}$ and PEFR.

It is important to note that the results highlight that high intensity exercise can have a faciliatory effect on the lungs, as measured by $\mathrm{FEV}_{1}$ values. It may be that a three days exercise program, which promotes regular and forceful inflation and deflation of the lungs, strengthens the actions of the respiratory muscles. The students' physical exertions could have helped to create reduced resistance to respiration and given the respiratory muscles the capacity for endurance training. This is likely to be an explanation for the significant difference in FVC values noted in this study ${ }^{3}$. The PEFR saw no difference emerging in pre and post test results. Flow rates are affected by the amount of effort expended, so during training they adapt to the often-higher ventilatory load, and this shows an absence of adaptive changes in the form of dynamic function. It would be useful to repeat this exercise program and extend it over five or six sessions, to see whether this might affect structural changes which could contribute to less compression of airways at lower lung volumes, and the subsequent improvement in the flow rate ${ }^{15}$.

It is clear, however, that the aerobic exercise improves ventilatory functions and increases the body's ability to use oxygen in a number of ways: (1) it tones all the muscles, improves circulation in the process, lowers blood pressure and reduces the heart's workload; (2) it strengthens the respiratory muscles and, since it can reduce airflow resistance, it also facilitates the flow of air, in and out of the lungs ${ }^{16)}$.

Our results are in line with those of a number of researchers. Emtner et al. ${ }^{16)}$ argued in favour of rehabilitation exercises in water over a ten-week period to improve the condition of asthma patients, and Berry and Walschlager ${ }^{17}$, demonstrated how 14 patients' $\mathrm{FEV}_{1}$ increased once they began doing swimming exercises. Farid et al. ${ }^{15}$ ) noted that pulmonary function could 
improve if patients undertook short duration sports activities and exercises. Enright et al. ${ }^{9)}$ carried out a study, which shows high intensity inspiratory muscle training results in contracted diaphragm thickness increasing, and a rise in lung volumes and exercise capacity in healthy individuals.

Khalili and Elkins ${ }^{10}$ ) discovered that exercise improves lung function to a small but nevertheless significant degree in children with learning difficulties. Durmus et al. ${ }^{2)}$ carried out research, which concluded that exercise effectively improves pulmonary function. Thaman et al. ${ }^{5)}$ examined post-training Border Security trainees and came to the conclusion that physical training improved their lung function parameters. Costa et al. ${ }^{18)}$ suggested that inverting inspiration/expiration could provide a method for carrying out respiratory exercises linked to the upper limbs, since this would minimize thoracoabdominal asynchrony in patients with COPD. Also, Azad et al. ${ }^{12)}$ suggested that overweight and clinically obese teenagers could benefit from aerobic exercise training, to improve lung function by strengthening their respiratory muscles. Shashikala and Ravipati ${ }^{14)}$ demonstrated that exercise training programs produced a rise in Pulmonary Function Test result values.

Grisbrook et al. ${ }^{13)}$ maintain that adults, who suffer pulmonary complications after burns, can nevertheless safely undertake high intensity exercise training. Halder ${ }^{19)}$ conclusively proved that men and children with asthma can benefit from taking part in supervised physical activities, such as yoga and Tai Chi Chuan, which improve lung function. Helal et al. ${ }^{20)}$ asserted that a single training session of arm ergometer exercise sufficed to improve healthy students' lung function. The authors suggested that further studies be carried out to discover if arm ergometer training programs have the same positive impact on pulmonary function in adults who suffer from respiratory problems.

We need to point out at this juncture that our results did not emulate the research findings carried out by Ghafoori ${ }^{21)}$, which could be because the two studies observed different administrative rules vis a vis the Sports Program. In our study, participants were high risk COPD adults who performed a three sessions high intensity aerobic exercise; Ghafoori, however, enrolled asthmatic individuals for a single session of tensile exercises, before measuring how this impacted on their $\mathrm{FEV}_{1}$ readings.

In conclusion, this study shows how high intensity arm ergometer exercises improved the lung function parameters in adults at high risk of COPD, after they had followed a short-term exercise program. Reporting the adult smokers with their abnormal lung function parameters can create smoking cessation strategy. Our findings underline the benefits of exercise programs and could be used to dissuade smokers from endangering their health, and in campaigns, which are run to persuade them to quit this habit.

\section{REFERENCES}

1) Mannino DM, Buist AS: Global burden of COPD: risk factors, prevalence, and future trends. Lancet, 2007, 370: 765-773. [Medline] [CrossRef]

2) Durmuş D, Alayli G, Uzun O, et al.: Effects of two exercise interventions on pulmonary functions in the patients with ankylosing spondylitis. Joint Bone Spine, 2009, 76: 150-155. [Medline] [CrossRef]

3) Pelkonen M, Notkola IL, Lakka T, et al.: Delaying decline in pulmonary function with physical activity: a 25-year follow-up. Am J Respir Crit Care Med, 2003, 168: 494-499. [Medline] [CrossRef]

4) Bassiony MM: Smoking in Saudi Arabia. Saudi Med J, 2009, 30: 876-881. [Medline]

5) Thaman RG, Arora A, Bachhel R: Effect of physical training on pulmonary function tests in border security force trainees of India. J Life Sci, 2010 , 2: 11-15.

6) West R, Shiffman S: Fast facts: smoking cessation. Oxford: Health Press, 2007.

7) James AL, Palmer LJ, Kicic E, et al.: Decline in lung function in the Busselton Health Study: the effects of asthma and cigarette smoking. Am J Respir Crit Care Med, 2005, 171: 109-114. [Medline] [CrossRef]

8) Baker JS, Thomas N, Davies B: Physiological biochemical and mechanical issues relating to resistive force selection during high-intensity cycle ergometer exercise. J Exerc Sci Fit, 2009, 7: 51-60. [CrossRef]

9) Enright SJ, Unnithan VB, Heward C, et al.: Effect of high-intensity inspiratory muscle training on lung volumes, diaphragm thickness, and exercise capacity in subjects who are healthy. Phys Ther, 2006, 86: 345-354. [Medline]

10) Khalili MA, Elkins MR: Aerobic exercise improves lung function in children with intellectual disability: a randomised trial. Aust J Physiother, 2009, 55: 171-175. [Medline] [CrossRef]

11) Hulke SM, Phatak MS: Effect of endurance training on lung function: a longitudinal study. Int J Biol Med Res, 2011, 2: 443-446.

12) Azad A, Gharakhanlou R, Niknam A, et al.: Effects of aerobic exercise on lung function in overweight and obese students. Tanaffos, 2011, 10: 24-31. [Medline]

13) Grisbrook TL, Wallman KE, Elliott CM, et al.: The effect of exercise training on pulmonary function and aerobic capacity in adults with burn. Burns, 2012, 38: 607-613. [Medline] [CrossRef]

14) Shashikala L, Ravipati S: Effects of exercise on pulmonary function test. Ind J Fund Appl Life Sci, 2011, 1: 230-231.

15) Farid R, Azad FJ, Atri AE, et al.: Effect of aerobic exercise training on pulmonary function and tolerance of activity in asthmatic patients. Iran J Allergy Asthma Immunol, 2005, 4: 133-138. [Medline]

16) Emtner M, Herala M, Stålenheim G: High-intensity physical training in adults with asthma. A 10-week rehabilitation program. Chest, 1996, 109: 323-330. [Medline] [CrossRef]

17) Berry MJ, Walschlager SA: Exercise training and chronic obstructive pulmonary disease: past and future research directions. J Cardiopulm Rehabil, 1998, 18: 181-191. [Medline] [CrossRef]

18) Costa D, Cancelliero KM, Ike D, et al.: Strategy for respiratory exercise pattern associated with upper limb movements in COPD patients. Clinics (Sao Paulo), 2011, 66: 299-305. [Medline] [CrossRef]

19) Halder K, Chatterjee A, Kain TC, et al.: Improvement in ventilatory function through yogic practices. Am J Med Sci, 2012, 5: 197-202.

20) Helal OF, Alayat MS, El Fiky AA, et al.: Impact of a single bout of high-intensity arm ergometer exercise on ventilatory function. Jokull, 2013 , 63: 339-356.

21) Ghafoori F: Effects of stretching exercises before physical activity on asthmatic patients, Thesis for master of sciences, College of Physical Education and Sport Sciences. Tehran: Tehran University, 1993, 75-76. 